\title{
COMPARABILIDADE DA MENSURAÇÃO DAS PROPRIEDADES PARA INVESTIMENTO DAS COMPANHIAS ABERTAS LISTADAS NA B3: UMA ANÁLISE SOB A ÓTICA DOS ÍNDICES T E H
}

COMPARABILITY OF THE MEASUREMENT OF INVESTMENTS PROPERTIES OF PUBLIC THE OPEN COMPANIES LISTED ON B3: AN ANALYSIS UNDER THE OPTICS OF T AND H

\author{
EMANUELLE FRASSON GUIMARÃES \\ Universidade Federal de Santa Catarina. Endereço: Campus \\ Universitário Reitor João David Ferreira Lima, Trindade | 88040-900 | \\ Florianópolis/SC / Brasil. \\ (D) $h$ ttp://orcid.org/0000-0002-3617-9968 \\ E-mail: emanuellef@hotmail.com.br
}

\section{SULIANI ROVER}

Universidade Federal de Santa Catarina. Endereço: Campus Universitário Reitor João David Ferreira Lima, Trindade | 88040-900 | Florianópolis/SC / Brasil.

(1) http://orcid.org/0000-0001-8612-2938

E-mail: sulianirover@gmail.com

\section{RESUMO}

As normas internacionais simbolizaram o início da harmonização dos padrões contábeis, que inclui, entre outras características qualitativas, a comparabilidade das informações contábeis. O CPC 28 (2009) permite escolhas contábeis entre o método de custo e o de valor justo na mensuração das propriedades para investimento (PPI). O objetivo geral deste artigo é verificar o nível de comparabilidade da mensuração após o reconhecimento inicial das PPI das companhias abertas listadas na B3. A amostra é composta pelas 91 empresas que apresentaram saldo de PPI em 2015. Os dados foram coletados nas demonstrações financeiras padronizadas e nas notas explicativas. Para verificar o nível de comparabilidade, foram utilizados o índice H introduzido por Van der Tas (1988) e o índice T proposto por Taplin (2004). Os resultados mostraram que $40 \%$ das empresas optaram pelo método de custo, $36 \%$ pelo método de valor justo, e $24 \%$ não divulgaram o método utilizado. Adicionalmente, observou-se que $58 \%$ das empresas optantes pelo método de custo divulgaram o valor justo. Quanto à análise de comparabilidade verificou-se um nível médio para a amostra, de acordo com a primeira abordagem dos índices $\mathrm{T}$ e $\mathrm{H}$, porém com valores bem próximos a um nível baixo.

Palavras-chave: Comparabilidade. Escolhas Contábeis. Propriedades para Investimento.

\section{ABSTRACT}

The international standards symbolized the beginning of the harmonization of accounting standards, which includes, among other qualitative characteristics, the comparability of accounting information. The CPC 28 (2009) allows for accounting choices between the cost and fair value method in the measurement of Investment Property (PPI). The general objective of this article is to verify the level of comparability of the measurement after the initial recognition 
of the PPI of the public companies listed on B3. The sample consisted of the 91 companies that presented PPI balance in 2015. The data were collected in the Financial Statements and in the Explanatory Notes. To verify the level of comparability, the $H$ index introduced by Van der Tas (1988) and the $T$ index proposed by Taplin (2004) were used. The results showed that $40 \%$ of the companies opted for the cost method, 36\% through the fair value method and $24 \%$ didn't disclose the method used. Additionally, it was observed that $58 \%$ of the companies using the cost method disclosed the fair value. As for the comparability analysis, an average level for the sample was verified according to the first approach of the $T$ and $H$ indexes, but with values very close to a low level.

Keywords: Comparability. Accounting Choices. Investment Property.

\section{INTRODUÇÃO}

O crescimento dos mercados de capitais em diferentes países promoveu uma maior preocupação quanto à evidenciação de informações relevantes para atrair novos investidores e aumentar o nível de confiança das empresas frente ao mercado (Vaz, Gonçalves, Niyama, \& Gonçalves, 2010). Assim, as normas internacionais, denominadas International Financial Reporting Standards (IFRS), elaboradas pelo International Accounting Standards Board (IASB), possuem como objetivo a harmonização dos padrões contábeis. No Brasil, o processo de convergência iniciou-se com a adoção da Lei no 11.638/2007, porém somente a partir de 2010 foram exigidas obrigatoriamente as instruções (Thomaz, Kronbauer, \& Schneider, 2015).

Segundo Cairns, Massoudi, Taplin e Tarca (2011), um dos principais objetivos da adoção das IFRS é melhorar a comparabilidade entre os relatórios financeiros. Essa característica qualitativa melhora a utilidade de uma informação contábil, pois permite a comparação de relatórios financeiros entre entidades diferentes ou entre a mesma entidade em períodos distintos (CPC $00 \mathrm{R} 1,2011)$. Para viabilizar a comparabilidade, algumas normas possibilitam à empresa optar quanto ao método de contabilização de determinados itens, ou seja, proporcionam as escolhas contábeis (accounting choices).

O Pronunciamento Técnico CPC 28 (2009) (International Accounting Standard [IAS] 40) trata de propriedades para investimento (PPI) e permite a escolha contábil entre o método de custo e o de valor justo na mensuração após o reconhecimento inicial dessas propriedades, que são mantidas para obtenção de renda e/ou valorização de capital.

Propriedade para investimento é a propriedade (terreno ou edifício - ou parte de edifício - ou ambos) mantida (pelo proprietário ou pelo arrendatário em arrendamento financeiro) para auferir aluguel ou para valorização do capital ou para ambas, e não para:

(a) uso na produção ou fornecimento de bens ou serviços ou para finalidades administrativas; ou

(b) venda no curso ordinário do negócio.

Propriedade ocupada pelo proprietário é a propriedade mantida (pelo proprietário ou pelo arrendatário sob arrendamento financeiro) para uso na produção ou fornecimento de bens ou serviços ou para finalidades administrativas. (CPC 28, 2009, p. 3)

Como a existência de escolhas contábeis na mensuração das PPI pode influenciar a comparabilidade das informações entre os relatórios financeiros, este estudo apresenta o seguinte problema de pesquisa: qual é o nível de comparabilidade da mensuração após o reconhecimento inicial das propriedades para investimento das companhias abertas listadas na Brasil, Bolsa, Balcão (B3)?

Nesse contexto, o objetivo geral é verificar o nível de comparabilidade da mensuração após o reconhecimento inicial das propriedades para investimento das companhias abertas listadas na B3. Por sua vez, os objetivos específicos podem ser definidos como: (i) identificar o método utilizado na mensuração das propriedades para investimento; (ii) averiguar o atendimento à finalidade de divulgação do valor justo prevista no CPC 28 (2009) e (iii) analisar o nível de comparabilidade das companhias abertas listadas na B3. 
A pesquisa justifica-se porque, apesar da harmonização dos padrões contábeis definida pelas normas internacionais, a flexibilidade na mensuração das PPI pode influenciar a qualidade e a comparabilidade das informações. Assim, a falta de padrões equivalentes pode prejudicar a relevância das informações e a tomada de decisão de usuários internos e externos.

Dessa forma, o estudo pretende contribuir para a linha de pesquisa que avalia a influência das escolhas contábeis na comparabilidade dos relatórios financeiros de empresas brasileiras, contribuindo para a literatura por meio da utilização de índices de comparabilidade. Poucos estudos preocupam-se com a mensuração do nível de comparabilidade por meio de índices, o que revela a existência de uma lacuna no tema.

Considerando que o CPC 28 (2009) permite métodos alternativos na mensuração posterior ao reconhecimento inicial das PPI, e que o CPC 00 R1 (2011) destaca a comparabilidade como uma característica qualitativa que deve estar presente nas informações contábeis, os resultados desta pesquisa buscam ainda motivar a reflexão por parte dos órgãos reguladores acerca da utilidade e dos impactos das escolhas contábeis nos relatórios financeiros.

\section{REFERENCIAL TEÓRICO}

\subsection{Comparabilidade e escolhas contábeis}

As informações contábeis possuem como um dos principais objetivos o auxílio aos usuários na tomada de decisão, como decisões de investimento ou mesmo para operações de crédito (Pereira, 2013). Assim, para serem relevantes, tais informações devem apresentar padrões equivalentes no que diz respeito à mensuração e à avaliação, a fim de que sejam comparáveis, independentemente da entidade, do país ou mesmo do período analisado (Araújo, Souza, \& Lemes, 2015; Coelho, Campagnoni, \& Rover, 2016).

Segundo a Estrutura Conceitual para Elaboração e Divulgação de Relatório ContábilFinanceiro - CPC 00 (R1), elaborada pelo Comitê de Pronunciamentos Contábeis (CPC) em 2011, a comparabilidade apresenta-se como uma das características qualitativas responsáveis por melhorar a utilidade de uma informação prestada aos usuários internos e externos e por assessorar a escolha entre alternativas equivalentes em relação à relevância e fidedignidade da informação. Além dessa, destacam-se a verificabilidade, a tempestividade e a compreensibilidade.

Tal característica de melhoria torna uma informação contábil mais útil a partir do momento em que pode ser comparada entre entidades diferentes ou entre a mesma entidade em períodos distintos. É importante ressaltar que essa característica qualitativa pressupõe a existência de, no mínimo, dois itens, para que sejam identificadas e compreendidas suas similaridades e diferenças (CPC 00 R1, 2011). A Estrutura Conceitual ainda destaca que: "embora um fenômeno econômico singular possa ser representado com fidedignidade de múltiplas formas, a discricionariedade na escolha de métodos contábeis alternativos para o mesmo fenômeno econômico diminui a comparabilidade" (CPC 00 R1, 2011, item QC 25, p. 18).

Nesse sentido, as normas internacionais reconhecem que métodos contábeis alternativos, conhecidos na literatura como "escolhas contábeis" (accounting choices), influenciam a comparabilidade de informações. De acordo com Fields, Lys e Vincent (2001), uma escolha contábil pode ser definida como qualquer decisão que tem como objetivo influenciar o output de um sistema de contabilidade, em relação a demonstrações contábeis, declarações fiscais e documentos regulatórios.

Botinha e Lemes (2016) buscaram possíveis explicações que justificassem a escolha diante de métodos contábeis distintos. Baseando-se na Teoria Positiva da Contabilidade, identificou-se a presença de três hipóteses que influenciam as escolhas contábeis: plano de incentivo, grau de endividamento e tamanho ou custos políticos. A primeira hipótese propõe que os administradores optarão pela alternativa que aumentar o lucro, adicionando valores para suas remunerações e bônus. A hipótese do grau de endividamento sugere que as 
empresas com maior nível de endividamento buscarão escolhas que aumentem o lucro para, por exemplo, captar investimentos. A última, por sua vez, indica que as maiores empresas priorizarão métodos contábeis que reduzam o lucro para diminuir os custos e a atenção política.

Além dessa perspectiva empírico-positivista, Pinto, Martins e Silva (2015) e Botinha e Lemes (2016) abordaram a influência do status quo para explicações de escolhas contábeis, o qual representa a manutenção de uma decisão para representar uma informação contábil, impedindo a mudança para evitar custos e riscos e permanecer na "zona de conforto". Destaca-se que a existência de métodos alternativos, apesar de em alguns casos auxiliar a empresa, influencia a tomada de decisão de usuários internos e externos, prejudica a aplicação da característica qualitativa de comparabilidade por permitir diferentes formas de mensuração para fatos semelhantes e reduz a utilidade das informações contábeis (Andrade, Silva, \& Malaquias, 2013).

Já Fearnley e Gray (2014), com o objetivo de investigar a adoção e a implementação das IFRS na União Europeia, por meio do exame das formas de mensuração das PPI de 66 empresas, no período de 2005 a 2010, verificaram que os fatores institucionais nacionais e os valores culturais continuam a ser mais importantes para explicar as escolhas contábeis na mensuração das PPI em relação aos fatores legais e de desenvolvimento do mercado de ações. Dessa maneira, é possível verificar os fatores que justificam por que muitas empresas mantêm a abordagem do método de custo na mensuração das propriedades para investimento.

As escolhas contábeis podem ser observadas na contabilização de programas de fidelização de clientes (Araújo et al., 2015); na mensuração, avaliação e evidenciação de estoques (Coelho et al., 2016); no tratamento contábil de ativos intangíveis (Souza, Silva, \& Costa, 2013) e na mensuração de ativos biológicos (Botinha, Santos, \& Lemes, 2013). Destaca-se como foco deste estudo a escolha contábil existente na mensuração posterior ao reconhecimento inicial das $\mathrm{PPI}$.

As pesquisas acerca da comparabilidade dividem-se principalmente em duas vertentes: a vertente que avalia o impacto da adoção das IFRS em variáveis contábeis internas e no mercado de capitais, analisando a melhoria da comparabilidade, e a que identifica o nível de comparabilidade a partir da existência de escolhas contábeis nas empresas (Souza \& Lemes, 2016). De acordo com Cole, Branson e Breesch (2008, 2009), a comparabilidade pode ser mensurada por técnicas baseadas em índices ou modelos estatísticos, além de os autores explorarem características dos índices H, C, I, V e T.

Van der Tas (1988) foi responsável por introduzir os primeiros índices de mensuração da comparabilidade das demonstrações contábeis: os índices $\mathrm{H}, \mathrm{C}$ e I. O índice Herfindahl $(\mathrm{H})$ foi inicialmente desenvolvido por Herfindahl, como uma medida de concentração industrial, e ajustado por Hirschman, porém introduzido apenas em 1988 por Van der Tas. Trata-se de um índice de concentração que pondera as frequências relativas de cada método contábil entre si. A frequência relativa é obtida pela divisão entre o número de empresas optantes por determinada prática contábil e o número total de empresas. $\mathrm{O}$ índice $\mathrm{H}$ revela uma maior comparabilidade quando as empresas concentram-se em um único método, e seus valores variam entre 0 e 1.

O índice de comparabilidade (C), também introduzido por Van der Tas (1988), tem como base o número de pares de empresas compatíveis e o número de emparelhamentos possíveis. Esse índice mensura a probabilidade de duas empresas selecionadas aleatoriamente possuírem contas comparáveis, variando entre 0 e 1 , e pode igualar-se ao índice $\mathrm{H}$ se o número de empresas for suficientemente grande e não houver relatórios múltiplos (Cole et al., 2008, 2009).

$\mathrm{O}$ índice I representa um índice de concentração, assim como o H, e surgiu como uma medida de comparabilidade internacional de materiais. É importante destacar que esse índice é um dos mais criticados entre os introduzidos por Van der Tas (1988). Ele indica o grau em que as empresas pertencentes a um país o aplicam ou apenas um número limitado de métodos alternativos, em comparação com empresas de outros países. Esse índice não leva em conta relatórios múltiplos contábeis, posto que a empresa pode ser associada apenas a um método alternativo. Além disso, ignora a não divulgação, não apresenta a comparabilidade parcial e seus valores flutuam entre 0 e 1 (Cole et al., 2008, 2009). 
De forma complementar aos índices de Van der Tas, Krisement introduziu em 1997 o índice de entropia, um método alternativo de índice de concentração. A entropia é uma medida inversa ao grau de comparabilidade. Assim, quando a entropia está em seu nível máximo, o nível de comparabilidade é considerado mínimo. Posteriormente, o índice $\mathrm{V}$ foi desenvolvido para determinar se existem ou não pequenas diferenças entre regiões quando são comparadas práticas contábeis (Cole et al., 2008).

O último índice destaca-se como um dos mais importantes e completos em pesquisas acerca do nível de comparabilidade: o índice T, introduzido por Taplin (2004), e que inclui todas as possibilidades dos anteriores, representando a probabilidade de duas empresas selecionadas aleatoriamente possuírem contas comparáveis. Em 2006, Taplin desenvolveu o Harmoniser Software, uma planilha do Excel, com o objetivo de calcular o índice (Cole et al., 2008). A Tabela 1 apresenta as principais características dos índices de comparabilidade $\mathrm{H}, \mathrm{C}$, $\mathrm{I}, \mathrm{V}$ e T.

Tabela 1

Características dos Índices de Comparabilidade

\begin{tabular}{l|c|c|c|c|c}
\multicolumn{1}{c|}{ Características dos İndices } & H & C & I & V & T \\
\hline Considera o número de empresas pesquisadas & Sim & Não & Não & Sim & Sim \\
\hline Considera o tamanho dos países examinados & Não & Não & Não & Não & Sim \\
\hline Considera a não divulgação (non-disclosure) & Sim & Sim & Sim & Não & Sim \\
\hline Considera múltiplas escolhas contábeis & Não & Sim & Não & Não & Sim \\
\hline Considera a comparabilidade parcial & Não & Não & Não & Não & Sim \\
\hline Sensibilidade à frequência zero & Não & Não & Sim & Não & Não \\
\hline Comparabilidade nacional (N), internacional (I) ou ambas (A) & N & N & I & I & A \\
\hline Capacidade de determinar um intervalo de probabilidade & Não & Não & Não & Não & Sim \\
\hline Permite a análise setorial com ponderações & Não & Não & Não & Não & Sim \\
\hline
\end{tabular}

Fonte: Adaptado de Cole, V., Branson, J., \& Breesch, D. (2008). An analysis of methods to measure the comparability of the consolidated financial statements of the European listed companies from the viewpoint of user. Accountancy \& Bedrijfskunde, 28(3), 1-31; Cole, V., Branson, J., \& Breesch, D. (2009). How to measure the comparability of financial statements?. International Journal of Managerial and Financial Accounting, 1(4), 379-397; e Souza, F. E. A., \& Lemes, S. (2016). A comparabilidade das escolhas contábeis na mensuração subsequente de ativos imobilizados, de ativos intangíveis e de propriedades para investimento em empresas da América do Sul. Revista Contabilidade \& Finanças, 27(71), 169-184. (2018).

Assim, percebe-se que o nível de comparabilidade das informações contábeis pode ser avaliado por meio de diferentes índices, porém destacam-se aqueles propostos por Van Der Tas (1988) e Taplin (2004). Araújo et al. (2015), Souza, Silva e Rech (2015) e Botinha et al. (2013) aplicaram o índice H (Herfindhal), enquanto Coelho et al. (2016) e Souza, Botinha, Silva e Lemes (2015) utilizaram o índice T.

\subsection{Propriedades para investimento}

A propriedade para investimento (PPI), item regulamentado pelo Pronunciamento Técnico CPC 28 (2009), referente à norma International Accounting Standard (IAS 40, Investment Property), pode ser compreendida como a propriedade mantida para obter rendas e/ou valorizar o capital. Ela diferencia-se da propriedade ocupada pelo proprietário por não ser utilizada para uso na produção, fornecimento de bens e serviços ou finalidades administrativas, e também por gerar fluxos de caixa independentes dos outros ativos pertencentes à entidade (CPC 28, 2009).

O CPC 28 (2009, p. 3 e 4) cita alguns exemplos de PPI, como "terrenos mantidos para valorização de capital a longo prazo e não para venda a curto prazo no decurso ordinário dos negócios" e "edifício que esteja desocupado, mas mantido para ser arrendado sob um ou mais arrendamentos operacionais".

Quanto à mensuração, as PPI inicialmente devem ser reconhecidas pelo custo - 0 preço de compra e dispêndios, como remunerações profissionais de serviços legais, impostos de transferência e outros. Após o reconhecimento inicial pelo custo, essas propriedades podem ser mensuradas pelo valor justo ou pelo custo, por meio da escolha da política contábil adotada pela entidade (CPC 28, 2009). O valor justo é definido como "o preço que seria recebido pela venda de um ativo ou que seria pago pela transferência de um passivo em uma transação não forçada entre participantes do mercado da data de mensuração" (CPC 28, 2009, p. 2). 
A entidade é obrigada a divulgar se aplica o método de custo ou o método de valor justo na mensuração posterior ao reconhecimento inicial dessas propriedades, além de outras informações, conforme o item 75 do CPC 28 (2009). É importante destacar que, mesmo que a entidade opte pelo método de custo, é obrigatória a mensuração do valor justo das PPI para finalidade de divulgação. Caso a escolha seja pelo método do valor justo, há ocorrência da finalidade de mensuração. Assim, constata-se que existe um "incentivo" para a mensuração por meio da política de valor justo, já que as entidades são obrigadas a mensurá-lo independentemente do método escolhido.

Como a mensuração das PPI após o reconhecimento inicial pode ser realizada por duas formas diferentes, é identificada a presença de escolhas contábeis que podem influenciar diretamente a comparabilidade das demonstrações contábeis de empresas de igual ou diferentes países. O IASB pronunciou-se alegando que permitiu a utilização das opções entre o método de custo e o método do valor justo por existirem países com mercados menos desenvolvidos e que poderiam ter uma dificuldade maior na adoção do valor justo (Costa, Silva, \& Laurencel, 2013). Dessa forma, pressupõe-se que o método do valor justo é preferível pelo IASB e que os mercados mais desenvolvidos tendem a utilizar essa política para mensuração posterior das PPI. Porém, diversos estudos aplicam-se nessa área, analisando qual método é mais aplicado e defendendo aquele que consideram representar uma informação contábil mais relevante.

\subsection{Estudos anteriores}

A escolha contábil entre o método do custo e o método do valor justo na mensuração das PPI e seu reflexo na característica qualitativa de comparabilidade foi estudada em artigos nacionais e internacionais, que contribuíram de forma significativa para a área. Enquanto alguns buscam verificar qual método é mais aplicado entre diferentes países ou entre o mesmo país, outros procuram identificar os fatores explicativos para a escolha contábil ou até mesmo verificar o nível de divulgação das propriedades frente às regras do CPC 28 (2009).

Costa et al. (2013) buscaram investigar quais são os incentivos econômicos para a escolha do método contábil na mensuração das PPI, demonstrando a ocorrência de cada método contábil e a qualidade das informações divulgadas, de acordo com as exigências do CPC 28 (2009). Na amostra de 36 empresas brasileiras não financeiras de capital aberto, os autores identificaram que 39\% adotaram o método do valor justo. Além disso, o incentivo econômico encontrado no estudo foi o porte da empresa, representado pela receita líquida. Com relação à divulgação, o estudo identificou que $68 \%$ das empresas optantes pelo método de custo divulgaram o valor justo em notas explicativas.

Dessa forma, os autores concluíram que empresas pertencentes ao mesmo setor apresentaram diferentes escolhas contábeis na mensuração das PPI, e que o nível de conformidade de divulgação, segundo o CPC 28 (2009), está abaixo do esperado. Tais constatações acometem a comparabilidade das demonstrações contábeis, dado que os usuários correm o risco de tomar decisões com base em informações levantadas por métodos diferentes, e a divulgação incompleta os priva de acesso a informações importantes. O estudo também confirmou a hipótese dos planos de incentivo, pois empresas com menor receita líquida tendem a mensurar suas propriedades pelo método do valor justo, aumentando o resultado.

Analisando as escolhas contábeis para PPI, durante os anos de 2009 e 2010, de 39 empresas pertencentes à Bolsa de Valores, Mercadorias e Futuros de São Paulo (BM\&FBovespa) e possíveis variáveis significativas relacionadas ao método, Andrade et al. (2013) verificaram que $44 \%$ adotaram o método do valor justo e, consequentemente, $56 \%$ adotaram o método do custo. Além disso, concluiu-se que nenhuma das variáveis do estudo apresentou relação com a escolha contábil para mensuração de PPI.

Kolozsvari, Marques e Macedo (2014) estudaram o segmento de exploração imobiliária de empreendimentos comerciais buscando definir o impacto da escolha entre as opções de políticas de mensuração nas PPI no resultado das empresas. Por meio de uma forma de cálculo para comparar resultados antes dos impostos, o estudo ilustrou que as empresas que utilizam o valor justo para mensuração possuem melhores resultados e rentabilidade. 
O artigo de Silva, Fonseca e Nogueira (2014) apresentou como objetivo o estudo do nível de conformidade das empresas durante o exercício de 2012, segundo as divulgações exigidas pelo Pronunciamento Técnico CPC 28 (2009). Dessa forma, os autores constataram que o nível de divulgação das empresas optantes pelo método de custo foi mais satisfatório que o das empresas que optaram pelo método de valor justo. As empresas pertencentes ao ramo de exploração de imóveis foram as que obtiveram maior percentual de divulgação, visto que apresentaram valores mais significativos para as PPI. Além disso, o estudo identificou dificuldades de evidenciação das PPI em demonstrações contábeis e notas explicativas, afetando a comparabilidade de informações e a tomada de decisão dos investidores.

Souza et al. (2015) estudaram o grau de comparabilidade e os fatores determinantes para a escolha contábil de mensuração, posterior ao reconhecimento inicial para PPI, de companhias abertas brasileiras e portuguesas entre 2010 e 2012. Por meio do índice $T$ ( $T$ index) para a medição da comparabilidade nacional e internacional e dos parâmetros estabelecidos por Souza et al. (2013), verificou-se que a comparabilidade brasileira é considerada média e vem decrescendo. Apesar de também apresentarem uma comparabilidade média, empresas portuguesas apresentaram valores estáveis entre 2010 e 2012.

A partir de uma análise dos relatórios anuais publicados em 2008 por 96 empresas chinesas, Taplin, Yuan e Brown (2014) verificaram que metade utiliza o valor justo para mensurar as propriedades para investimento. Por meio do índice $\mathrm{T}$, os autores constataram que empresas com influência internacional, ou seja, com transações internacionais e/ou listadas em bolsas de valores globais, estão mais propensas a utilizar a mensuração a valor justo.

A comparabilidade internacional entre Portugal e Brasil, no estudo de Souza et al. (2015), foi caracterizada como média, com valores próximos a uma comparabilidade baixa e decrescente ao longo dos anos. Com relação às variáveis explicativas para a escolha do método contábil, o estudo identificou big four, país, endividamento, relevância do saldo das propriedades e lucro líquido. $\mathrm{O}$ artigo apresentou como uma das principais contribuições a utilização do índice T.

Com o objetivo de identificar as possíveis características para as escolhas contábeis em companhias abertas da BM\&FBovespa e NYSE em PPI no ano de 2013, Botinha e Lemes (2016) concluíram que ocorreu uma maior utilização do método do custo pelas empresas em ambas as bolsas e que as variáveis significativas para decisão da política contábil foram big four, tamanho da empresa, relevância do saldo das PPI e o setor de Telecomunicações.

Os autores encontraram resultados que fornecem indícios da existência de um status quo, que diz respeito à "zona de conforto", e não reconheceram que empresas pertencentes a mercados mais desenvolvidos teriam maior aceitação ao valor justo, já que os percentuais para adoção desse método entre NYSE - mercado de capitais mais desenvolvido - e BM\&FBovespa foram próximos. Quanto à finalidade de divulgação do valor justo, Botinha e Lemes (2016) constataram que $68 \%$ das empresas optantes pelo método de custo respeitam a obrigação presente no CPC 28 (2009) quanto ao disclosure contábil das PPI, porém o cenário das duas bolsas de valores apresentou-se distinto. Enquanto na NYSE 86\% das empresas divulgaram o valor justo, na BM\&FBovespa apenas $55 \%$ das empresas o fizeram. Além disso, o estudo contribuiu para a temática por meio de informações acerca da teoria positiva da contabilidade de Watts e Zimmerman (1986) e da teoria da agência.

Kwinto e Voss (2016), por meio do estudo das formas de reconhecimento, mensuração e divulgação e da forma de apresentação das informações acerca das PPI nas demonstrações financeiras padronizadas, verificaram que aproximadamente $90 \%$ das empresas pertencentes aos maiores grupos da Bolsa de Valores de Varsóvia (Warsaw Stock Exchange) utilizam o método de custo na mensuração das PPI, e que o índice baixo de aplicação do método do valor justo pode estar relacionado à dificuldade na mensuração e ao fato de estar em uso em um curto período de tempo.

As pesquisas nacionais acerca das PPI preocupam-se principalmente com a investigação das variáveis que podem explicar a escolha contábil entre o método de custo ou de valor justo na mensuração após o reconhecimento inicial. É possível observar que poucas 
delas aplicaram índices de comparabilidade, o que revela uma lacuna no tema. Dessa forma, tem-se a justificativa para investigar a comparabilidade da mensuração das PPI, que influencia a relevância de informações contábeis e a tomada de decisão de usuários internos e externos.

\section{PROCEDIMENTOS METODOLÓGICOS}

O presente artigo possui como característica uma classificação metodológica descritiva porque estuda o comportamento das empresas quanto à escolha entre os métodos de mensuração das $\mathrm{PPI}$. As pesquisas descritivas procuram relatar aspectos de uma população ou fenômeno e até mesmo estabelecer conexões entre as variáveis analisadas (Gil, 2008).

Quanto aos procedimentos, a pesquisa representa um levantamento (survey). De acordo com Martins e Theóphilo (2009, p. 60), "os levantamentos são próprios para os casos em que o pesquisador deseja responder a questões acerca da distribuição de uma variável ou das relações entre características de pessoas ou grupos". A abordagem metodológica identifica-se como quali-quantitativa, posto que apresenta dados quantificados e analisados por meio de técnicas estatísticas e outros que representam descrições não suscetíveis de mensuração (Martins \& Theóphilo, 2009).

A população em estudo inclui as 457 empresas abertas listadas na B3, pertencentes a dez setores distintos. É importante destacar que foram excluídas 13 empresas que não apresentaram demonstrações financeiras padronizadas (DFP) datadas de 31/12/2015. Para a definição da amostra, foram coletadas informações referentes à existência de PPI nas DFP e nas notas explicativas (NE), sendo selecionadas as empresas que apresentaram saldos para essas propriedades no exercício social de 2015.

A Tabela 2 apresenta o número total de empresas por setor listadas na B3 e a quantidade de empresas que possuem e não possuem saldo para as PPI no ano de 2015. Dessa forma, conclui-se que de um total de 457 organizações, a amostra do estudo é composta por 91 empresas dos dez setores distintos listados. Além disso, verifica-se que a amostra representa $20 \%$ da população e que o setor com maior porcentagem de empresas com saldo em PPI é o de consumo não cíclico.

Tabela 2

\section{População e Amostra}

\begin{tabular}{|c|c|c|c|c|c|}
\hline Setor & OBS. & № Empresas sem PPI & $\%$ & № Empresas com PPI & $\%$ \\
\hline Bens Industriais & 76 & 65 & $86 \%$ & 11 & $14 \%$ \\
\hline Consumo Cíclico & 85 & 65 & $76 \%$ & 20 & $24 \%$ \\
\hline Consumo Não Cíclico & 20 & 13 & $65 \%$ & 7 & $35 \%$ \\
\hline Financeiro e Outros & 135 & 109 & $81 \%$ & 26 & $19 \%$ \\
\hline Materiais Básicos & 34 & 29 & $85 \%$ & 5 & $15 \%$ \\
\hline Petróleo, Gás e Biocombustíveis & 11 & 9 & $82 \%$ & 2 & $18 \%$ \\
\hline Saúde & 13 & 10 & $77 \%$ & 3 & $23 \%$ \\
\hline Tecnologia da Informação & 8 & 7 & $88 \%$ & 1 & $13 \%$ \\
\hline Telecomunicações & 7 & 6 & $86 \%$ & 1 & $14 \%$ \\
\hline Utilidade Pública & 68 & 53 & $78 \%$ & 15 & $22 \%$ \\
\hline Total & 457 & 366 & $80 \%$ & 91 & $20 \%$ \\
\hline
\end{tabular}

Fonte: Elaborado pelos autores (2018).

A técnica de coleta de dados foi a análise de conteúdo, realizada nas DFP e nas NE das empresas com relação às PPI. Dessa forma, foram investigadas informações quanto ao valor das PPI, ao método escolhido para mensuração após o reconhecimento inicial e ao atendimento do requisito de divulgação do valor justo das empresas que optaram pelo método de custo, conforme exposto no CPC 28 (2009).

Para verificar o nível de comparabilidade das empresas, foram aplicados o índice $\mathrm{H}$, proposto por Van der Tas (1988), e o índice T ( $T$ index), proposto por Taplin (2004). O índice H é calculado por meio da ponderação de frequências relativas dos métodos contábeis alternativos entre si. A frequência de um método contábil compreende o número de empresas que optam pelo referido método. A frequência relativa é obtida pelo número de empresas optantes por um determinado método contábil dividido pelo número total de empresas. Assim, 
o índice revela um maior nível de comparabilidade quando as empresas concentram-se em apenas um ou em um número limitado de práticas contábeis (Van der Tas, 1988).

A forma para o cálculo do índice H é apresentada na pesquisa de Van der Tas (1988). A variável $n$ representa o número de métodos contábeis alternativos, e a variável $P i$ a frequência relativa do método contábil $i$.

$$
H=\sum_{i=1}^{n} p_{i}^{2}
$$

Figura 1. Fórmula Geral do Índice H

Fonte: Van der Tas, L. G. (1988). Measuring harmonisation of financial reporting practice. Accounting and business research, 18(70), 157-169.

O índice T determina se as contas contábeis de empresas distintas são comparavéis, de acordo com os métodos contábeis escolhidos (Coelho et al., 2016). A fórmula geral para o cálculo do índice T é apresentada no estudo de Taplin (2004, p. 61):

$$
T=\sum_{i=1}^{N} \sum_{j=1}^{N} \sum_{k=1}^{M} \sum_{l=1}^{M} \alpha_{k l} \beta_{i j} P_{k i} P_{l j}
$$

Figura 2. Fórmula Geral do Índice T

Fonte: Taplin, R. H. (2004). A unified approach to the measurement of international accounting harmony. Accounting and Business Research, 34(1), 57-73.

As variáveis da fórmula são, de acordo com Taplin (2004, p. 61):

$\alpha \mathrm{kl}$ - o coeficiente de comparabilidade entre os métodos contábeis $\mathrm{k}$ e l;

Bij - a ponderação para a comparação entre empresas dos países i e j;

$P k i$ - a proporção de empresas no país i que utilizam o método contábil k;

Plj - a proporção de empresas no país j que utilizam o método contábil i;

$\mathrm{N}$ - a quantidade de países (1 a N);

$\mathrm{M}$ - a quantidade de métodos contábeis (1 a $\mathrm{M})$.

O valor mínimo para o índice $\mathrm{H}$ e para o índice $\mathrm{T}$ é 0 , e indica o nível de não comparabilidade. O valor máximo é 1 , e indica o nível total de comparabilidade. Para a interpretação dos valores dos dois índices, demonstrada na Tabela 3, foi utilizada a escala adaptada, presente nas pesquisas de Souza et al. (2015) e Souza et al. (2013).

Tabela 3

\section{Interpretação do Índice H e T}

\begin{tabular}{c|c}
\hline Índice T & Nível de Comparabilidade \\
\hline Entre 0,700 e 1,000 & Alta \\
\hline Entre 0,500 e 0,699 & Média \\
\hline Entre 0,000 e 0,499 & Baixa \\
\hline
\end{tabular}

Fonte: Souza, F. E. A., Botinha, R. A., Silva, P. R., \& Lemes, S. (2015). A comparabilidade das escolhas contábeis na avaliação posterior de propriedades para investimento: uma análise das companhias abertas brasileiras e portuguesas. Revista Contabilidade \& Finanças, 26(68), 154-166. (2018)

O índice $\mathrm{H}$ foi calculado por meio do Microsoft Excel e o índice T por meio do programa T-Index Calculator, disponibilizado pelo professor Ross H. Taplin por endereço eletrônico. Foram utilizadas as seguintes opções para o cálculo do índice $\mathrm{T}$ : 1 (b) ponderação empresa/país: os países são ponderados igualmente; 2 (a) foco internacional: comparações são realizadas entre todas companhias independentemente de seu país; 3 (a) diversas políticas contábeis: múltiplas políticas contábeis não são permitidas, já que são comparáveis apenas com elas mesmas; e na etapa 4 foram escolhidas as opções (a), (b) e (c), que geraram três diferentes abordagens do índice T e que serão analisadas no estudo (Taplin, 2004). 


\section{ANÁLISE DOS RESULTADOS}

\subsection{Métodos de mensuração em propriedades para investimento}

As empresas da amostra que apresentaram saldos para as PPI no exercíco social de 2015 foram inicialmente analisadas quanto ao método de mensuração. A Tabela 4 expõe a quantidade de empresas por setor que optaram pelo método de custo, pelo método do valor justo ou que não divulgaram o método.

Tabela 4

Método de Mensuração das PPI em 2015

\begin{tabular}{c|c|c|c|c|c|c|c}
\hline Setor & Custo & $\%$ & Valor Justo & $\%$ & Não Divulgado & $\%$ & Total \\
\hline Bens Industriais & 4 & $36 \%$ & 6 & $55 \%$ & 1 & $9 \%$ & $\mathbf{1 1}$ \\
\hline Consumo Cíclico & 5 & $25 \%$ & 9 & $45 \%$ & 6 & $30 \%$ & $\mathbf{2 0}$ \\
\hline Consumo Não Cíclico & 3 & $43 \%$ & 4 & $57 \%$ & 0 & $0 \%$ & $\mathbf{7}$ \\
\hline Financeiro e Outros & 14 & $54 \%$ & 10 & $38 \%$ & 2 & $8 \%$ & $\mathbf{2 6}$ \\
\hline Materiais Básicos & 2 & $40 \%$ & 2 & $40 \%$ & 1 & $20 \%$ & $\mathbf{5}$ \\
\hline Petróleo, Gás e Biocombustíveis & 0 & $0 \%$ & 2 & $100 \%$ & 0 & $0 \%$ & $\mathbf{2}$ \\
\hline Saúde & 1 & $33 \%$ & 0 & $0 \%$ & 2 & $67 \%$ & $\mathbf{3}$ \\
\hline Tecnologia da Informação & 1 & $100 \%$ & 0 & $0 \%$ & 0 & $0 \%$ & $\mathbf{1}$ \\
\hline Telecomunicações & 1 & $100 \%$ & 0 & $0 \%$ & 0 & $0 \%$ & $\mathbf{1}$ \\
\hline Utilidade Pública & 5 & $33 \%$ & 0 & $0 \%$ & 10 & $67 \%$ & $\mathbf{1 5}$ \\
\hline Total & $\mathbf{3 6}$ & $\mathbf{4 0 \%}$ & $\mathbf{3 3}$ & $\mathbf{3 6 \%}$ & $\mathbf{2 2}$ & $\mathbf{2 4 \%}$ & $\mathbf{9 1}$ \\
\hline
\end{tabular}

Fonte: Elaborado pelos autores (2018)

É possível verificar, na Tabela 4, que $100 \%$ dos setores de Tecnologia da Informação e Telecomunicações aplicou o método de custo. Porém, como cada setor engloba apenas uma empresa, essa informação não é relevante para o estudo. O setor Financeiro e Outros contou com 14 empresas optantes pelo método de custo dentre 26 analisadas, ou seja, 54\% das empresas escolheram o método. O número pode ser explicado pelo fato de o setor incluir os segmentos relacionados à exploração imobiliária, foco de outros estudos, como o de Kolozsvari et al. (2014). Esse setor é o que possui maior número de empresas da amostra estudada (26) e também o maior número de empresas que aplicaram o método de custo (14). Kwinto e Voss (2016) verificaram que aproximadamente $40 \%$ das empresas de serviços financeiros da Bolsa de Valores de Varsóvia aplicaram o método do valor justo na mensuração das PPI.

Por meio da análise das empresas que aplicaram o valor justo, constata-se que $100 \%$ das empresas do setor de Petróleo, Gás e Biocombustíveis - que abrange duas empresas optaram por esse método. Nota-se também que as empresas pertencentes ao setor de Saúde e Utilidade Pública não utilizaram esse método de mensuração e suas alíquotas de não divulgação do método, conforme o item 75 do CPC 28 (2009), foram as mais altas (67\% das empresas da amostra do setor). Além disso, verifica-se que os setores de Bens Industriais, Consumo Cíclico, Consumo Não Cíclico e Petróleo, Gás e Biocombustíveis apresentaram mais empresas que escolheram como método de mensuração para as PPI o valor justo em relação ao custo.

Dentre um total de 91 empresas analisadas, 69 divulgaram e 22 não divulgaram o método escolhido para mensurar as PPI. Dessa forma, $24 \%$ das empresas não cumprem o item 75 exposto pelo CPC 28 (2009), que aborda a obrigatoriedade da entidade divulgar o método adotado. Além disso, 36 empresas aplicaram o método de custo (40\%) e 33 aplicaram o método do valor justo (36\%). Se forem desconsideradas para análise as empresas que não divulgaram o método de mensuração, $52 \%$ optaram pelo custo e $48 \%$ pelo valor justo. Dessa forma, a maior parte das empresas optou pelo método de custo, porém nota-se pouca diferença de aplicação entre os métodos e alto índice de não divulgação.

É importante verificar se as empresas estudadas atenderam ao CPC 28 (2009) quanto à obrigatoriedade da divulgação do valor justo, seja por finalidade de mensuração ou por finalidade de divulgação (optantes pelo método de custo). Assim, a Tabela 5 mostra as empresas que aplicaram o método de custo para a mensuração após o reconhecimento inicial das PPI. 
Tabela 5

Divulgação do Valor Justo para Empresas Optantes pelo Método de Custo em 2015

\begin{tabular}{c|c|c|c}
\hline Setor & Custo & Divulgação Valor Justo & \% Divulgação Valor Justo \\
\hline Bens Industriais & 4 & 4 & $100 \%$ \\
\hline Materiais Básicos & 2 & 2 & $100 \%$ \\
\hline Saúde & 1 & 1 & $100 \%$ \\
\hline Tecnologia da Informação & 1 & 1 & $100 \%$ \\
\hline Telecomunicações & 1 & 1 & $100 \%$ \\
\hline Financeiro e Outros & 14 & 8 & $57 \%$ \\
\hline Utilidade Pública & 5 & 2 & $40 \%$ \\
\hline Consumo Não Cíclico & 3 & 1 & $33 \%$ \\
\hline Consumo Cíclico & 5 & 1 & $20 \%$ \\
\hline Petróleo, Gás e Biocombustíveis & 0 & 0 & - \\
\hline Total & $\mathbf{3 6}$ & $\mathbf{2 1}$ & $\mathbf{5 8 \%}$ \\
\hline
\end{tabular}

Fonte: Elaborado pelos autores (2018).

Constata-se que $100 \%$ das empresas do setor de Bens Industriais, Materiais Básicos, Saúde, Tecnologia da Informação e Telecomunicações - que adotaram como escolha contábil na mensuração das PPI o método de custo - cumpriram a finalidade de divulgação do valor justo. O setor de Consumo Cíclico apresentou o menor índice de divulgação (20\%), dado que, entre cinco empresas que aplicaram o método de custo, apenas uma divulgou o valor justo das PPI. Percebe-se, pela análise dos valores totais, que entre as empresas que compõem a amostra, sem distinção de setores, $58 \%$ atendem à obrigatoriedade da divulgação do valor justo. Ou seja, entre as 36 empresas que aplicaram o método de custo, 21 divulgaram o valor justo complementarmente.

\subsection{Nível de comparabilidade}

O índice $T$ permite demonstrar o nível de comparabilidade perante os métodos contábeis aplicados pelas empresas da amostra. Taplin (2004) evidencia a existência de diferentes abordagens para o cálculo do índice T quando a amostra inclui empresas que não divulgaram o método contábil escolhido (non-disclosure), partindo da premissa de que a não divulgação seja o último método contábil. A primeira abordagem (T1) exclui as empresas que não divulgaram o método contábil para o cálculo do índice. A remoção da não divulgação pode ser razoável quando a intenção é mensurar o nível de comparabilidade das companhias para as quais essa política contábil representa um problema (Taplin, 2004). Dessa forma, o índice T1 apresentará a comparabilidade dentre as empresas que apresentaram o método de mensuração das PPI.

A segunda abordagem (T2) inclui todas as empresas da amostra, ou seja, as empresas que não divulgaram o método contábil adotado são consideradas comparáveis a todas as outras, independentemente do método. De acordo com Taplin (2004), essa abordagem é razoável se for aceita a ideia de que a não divulgação é resultado de uma não aplicabilidade. Assim, as contas de uma empresa que não apresentou o método contábil devem ser comparadas a quaisquer outras empresas.

$\mathrm{Na}$ terceira abordagem (T3) a não divulgação não é comparável a qualquer dos outros métodos contábeis. Coelho et al. (2016) esclarecem essa abordagem ao expor que as empresas que não informaram o método contábil escolhido são consideradas para o cálculo do índice, porém não são comparadas às demais organizações.

Assim, como a amostra do presente estudo contou com empresas que não divulgaram - método contábil adotado na mensuração das $\mathrm{PPI}$, foram calculadas as três abordagens apresentadas anteriormente para cada setor. Os valores dos índices $T$ obtidos são demonstrados na Tabela 6, assim como a interpretação de acordo com a escala abordada no capítulo dos procedimentos metodológicos. 
Tabela 6

Índices T e Nível de Comparabilidade dos Setores

\begin{tabular}{c|c|c|c|c|c|c}
\hline Setor / Índice & T1 & Nível & T2 & Nível & T3 & Nível \\
\hline Petróleo, Gás e Biocombustíveis & 1,00 & Alta & 1,00 & Alta & 1,00 & Alta \\
\hline Tecnologia da Informação & 1,00 & Alta & 1,00 & Alta & 1,00 & Alta \\
\hline Telecomunicações & 1,00 & Alta & 1,00 & Alta & 1,00 & Alta \\
\hline Saúde & 1,00 & Alta & 1,00 & Alta & 0,11 & Baixa \\
\hline Utilidade Pública & 1,00 & Alta & 1,00 & Alta & 0,11 & Baixa \\
\hline Consumo Cíclico & 0,54 & Média & 0,78 & Alta & 0,26 & Baixa \\
\hline Financeiro e Outros & 0,51 & Média & 0,59 & Média & 0,44 & Baixa \\
\hline Bens Industriais & 0,52 & Média & 0,60 & Média & 0,43 & Baixa \\
\hline Consumo Não Cíclico & 0,51 & Média & 0,51 & Média & 0,51 & Média \\
\hline Materiais Básicos & 0,50 & Média & 0,68 & Média & 0,32 & Baixa \\
\hline
\end{tabular}

Fonte: Elaborado pelos autores (2018).

Conforme a Tabela 6, é possível verificar que os setores de Petróleo, Gás e Biocombustíveis, Tecnologia da Informação e Telecomunicações apresentaram um índice T de harmonia, independentemente da abordagem, no valor de 1,00. Ou seja, as empresas possuem um nível total de comparabilidade. Os índices mostraram-se semelhantes nas três abordagens, uma vez que não ocorreram casos de não divulgação a respeito do método de mensuração das PPI. Além disso, é importante destacar que são poucas as companhias da amostra em geral pertencentes a esses setores (2 - petróleo, gás e biocombustíveis; 1 Tecnologia da Informação; 1 - Telecomunicações).

Os setores de Saúde e Utilidade Pública apresentaram índices T similares: T1 e T2 foram iguais a 1,00 e T3 apresentou o valor de 0,11. Dessa forma, as duas primeiras abordagens indicam alta comparabilidade, porém a última abordagem revela uma baixa comparabilidade. Tal fato pode ser explicado pela alta representatividade de empresas do setor que não evidenciaram o método contábil de mensuração, e pelo fato de que as demais optaram apenas por um dos dois métodos (no caso, o método de custo).

As empresas pertencentes ao setor de Consumo Cíclico apresentaram diferentes níveis de comparabilidade, de acordo com a abordagem: uma média comparabilidade (T1), uma alta comparabilidade (T2) e uma baixa comparabilidade (T3). O valor do índice T de harmonia obtido pela primeira abordagem - na qual as empresas que não divulgaram o método são ignoradas no cálculo - revela que, se duas empresas desse setor forem selecionadas aleatoriamente, há $54 \%$ de chance de elas adotarem o mesmo método na mensuração das PPI. Dessa forma, conceitua-se como um nível médio de comparabilidade. Com relação ao valor do índice T2 $(0,78)$, revelou-se uma alta comparabilidade entre as empresas do setor.

O setor Financeiro e Outros, que abrange o maior número de empresas da amostra, apresentou um nível de comparabilidade médio pela ótica das duas primeiras abordagens e um nível de comparabilidade baixo pela última abordagem. A interpretação de T1 permite concluir que há $51 \%$ de chance de duas empresas separadas aleatoriamente mensurarem as PPI pelo mesmo método contábil, seja ele o método de custo ou o método de valor justo.

As empresas do setor de Bens Industriais apresentam média comparabilidade, segundo as duas primeiras abordagens do índice T, e uma baixa comparabilidade, de acordo com a terceira abordagem. O setor de Consumo Não Cíclico apresentou uma comparabilidade média e os mesmos valores para as três diferentes abordagens, pois todas as empresas divulgaram o método contábil adotado, com a probabilidade de $51 \%$ de duas empresas adotarem o mesmo método de mensuração. Por último, o setor de Materiais Básicos apresentou um nível médio de comparabilidade em T1 e T2 e uma baixa comparabilidade em T3.

Apesar de Van der Tas (1988) não evidenciar em seus estudos a presença de diferentes abordagens para o cálculo do índice $\mathrm{H}$, quando na amostra encontram-se empresas que não divulgaram o método contábil para mensuração, a presente pesquisa definiu duas abordagens para o índice, com o propósito de comparar os resultados entre esse índice e o apresentado por Taplin. A primeira abordagem $(\mathrm{H} 1)$, assim como $\mathrm{T} 1$, exclui as empresas que não divulgaram o método contábil para o cômputo do índice, e a segunda abordagem (H2) inclui todas as empresas, adotando a não divulgação como um dos métodos contábeis existentes. 
A Tabela 7 expõe as frequências relativas para os métodos de custo e valor justo na mensuração das PPI, excluindo as empresas que não divulgaram o método para a definição dos valores do índice $\mathrm{H} 1$ por setor. Além disso, a tabela traz a interpretação dos valores do índice de acordo com a escala definida nos procedimentos metodológicos.

Tabela 7

Índice H1 e Nível de Comparabilidade dos Setores

\begin{tabular}{c|c|c|c|c}
\hline Setor & Frequência Relativa Custo & Frequência Relativa Valor Justo & H1 & Nível \\
\hline Petróleo, Gás e Biocomb. & 0,00 & 1,00 & 1,00 & Alta \\
\hline Tecnologia da Informação & 1,00 & 0,00 & 1,00 & Alta \\
\hline Telecomunicações & 1,00 & 0,00 & 1,00 & Alta \\
\hline Saúde & 1,00 & 0,00 & 1,00 & Alta \\
\hline Utilidade Pública & 1,00 & 0,00 & 1,00 & Alta \\
\hline Consumo Cíclico & 0,36 & 0,64 & 0,54 & Média \\
\hline Bens Industriais & 0,40 & 0,60 & 0,52 & Média \\
\hline Consumo Não Cíclico & 0,43 & 0,57 & 0,51 & Média \\
\hline Financeiro e Outros & 0,58 & 0,42 & 0,51 & Média \\
\hline Materiais Básicos & 0,50 & 0,50 & 0,50 & Média \\
\hline Fonte: Elaborado pelos autores (2018). & & &
\end{tabular}

Como o índice Herfindahl representa uma medida de concentração, um maior nível de comparabilidade ocorrerá quando as empresas concentrarem-se em apenas um ou em um número limitado de métodos contábeis (Van der Tas, 1988). Assim como as empresas pertencentes aos setores de Petróleo, Gás e Biocombustíveis, Tecnologia da Informação, Telecomunicações, Saúde e Utilidade Pública, ao se concentrarem em apenas uma das práticas contábeis na mensuração das PPI, apresentaram um nível total de comparabilidade.

Os setores de Consumo Cíclico, Bens Industriais e Consumo Não Cíclico apresentaram uma frequência relativa para o método de valor justo superior em relação à frequência relativa para o método de custo e um nível de comparabilidade médio. Destaca-se nesses casos que, quanto maior a frequência relativa para o valor justo, maiores são os valores registrados no índice $\mathrm{H}$. O setor Financeiro e Outros apresentou uma frequência relativa superior para 0 método de custo e um nível médio de comparabilidade. Quanto às empresas do setor de Materiais Básicos, como a frequência relativa igualou-se entre os dois métodos, o valor do índice $\mathrm{H}$ foi de 0,50 .

É importante salientar que os valores do índice $\mathrm{H} 1$ assemelham-se aos valores do índice T1 pelas seguintes razões: ambos descartaram da amostra as empresas que não divulgaram a prática contábil adotada na mensuração das PPI (non-disclosure), e a pesquisa analisou empresas de um único país.

Os valores referentes à segunda abordagem do índice $\mathrm{H}$ e às interpretações acerca do nível de comparabilidade, assim como as frequências relativas para os métodos de custo, valor justo e método não divulgado, são apresentados na Tabela 8.

Tabela 8

Índice $\mathrm{H} 2$ e Nível de Comparabilidade dos Setores

\begin{tabular}{c|c|c|c|c|c}
\hline Setor & $\begin{array}{c}\text { Frequência } \\
\text { Relativa Custo }\end{array}$ & $\begin{array}{c}\text { Frequência Relativa } \\
\text { Valor Justo }\end{array}$ & $\begin{array}{c}\text { Frequência Relativa } \\
\text { Método Não Divulgado }\end{array}$ & H2 & Nível \\
\hline Petróleo, Gás e Biocomb. & 0,00 & 1,00 & 0,00 & 1,00 & Alta \\
\hline Tecnologia da Informação & 1,00 & 0,00 & 0,00 & 1,00 & Alta \\
\hline Telecomunicações & 1,00 & 0,00 & 0,00 & 1,00 & Alta \\
\hline Saúde & 0,33 & 0,00 & 0,67 & 0,56 & Média \\
\hline Utilidade Pública & 0,33 & 0,00 & 0,67 & 0,56 & Média \\
\hline Consumo Não Cíclico & 0,43 & 0,57 & 0,00 & 0,51 & Média \\
\hline Bens Industriais & 0,36 & 0,55 & 0,09 & 0,44 & Baixa \\
\hline Financeiro e Outros & 0,54 & 0,38 & 0,08 & 0,44 & Baixa \\
\hline Consumo Cíclico & 0,25 & 0,45 & 0,30 & 0,36 & Baixa \\
\hline Materiais Básicos & 0,40 & 0,40 & 0,20 & 0,36 & Baixa \\
\hline
\end{tabular}

Fonte: Elaborado pelos autores (2018). 
Conforme a Tabela 8, verifica-se que os setores de Petróleo, Gás e Biocombustíveis, Tecnologia da Informação e Telecomunicações apresentaram frequência relativa nula para o método não divulgado e um nível total de comparabilidade já que as empresas concentraramse em apenas um dos métodos possíveis para mensuração das PPI. Os setores de Saúde e Utilidade Pública retrataram as maiores concentrações de frequência para o método não divulgado e frequência nula para o método do valor justo, além de um nível de comparabilidade médio $(0,56)$. Todas as empresas pertencentes ao setor de Consumo Não Cíclico divulgaram por qual método optaram na mensuração das PPI, e o valor do índice $\mathrm{H}$ apontou um nível médio de comparabilidade para o setor. Os valores de $\mathrm{H} 2$ para empresas integrantes dos setores Financeiro e Outros, Consumo Cíclico e Materiais Básicos retrataram um nível baixo de comparabilidade entre as demonstrações contábeis de cada setor.

A Tabela 9 apresenta as três abordagens do índice $\mathrm{T}$ e as duas abordagens do índice $\mathrm{H}$ para a amostra que abrange 91 empresas. A escala de comparabilidade utilizada está presente nos estudos de Souza et al. (2015) e Souza et al. (2013).

Tabela 9

Índice T e H da Amostra

\begin{tabular}{c|c|c|c|c|c|c|c|c|c|c}
\hline Amostra / Índice & T1 & Nível & T2 & Nível & T3 & Nível & H1 & Nível & H2 & Nível \\
\hline 91 empresas & 0,50 & Média & 0,71 & Alta & 0,29 & Baixa & 0,50 & Média & 0,35 & Baixa \\
\hline
\end{tabular}

Fonte: Elaborado pelos autores (2018).

A primeira abordagem do índice $\mathrm{T}$, que desconsidera para a base de cálculo as empresas que não divulgaram o método contábil de mensuração das PPI, indica um nível médio de comparabilidade, porém com valor bem próximo ao de uma comparabilidade baixa. Como o estudo utilizou empresas de um único país, e a primeira abordagem do índice $\mathrm{H}$ também exclui o non-disclosure no cômputo, os valores de $\mathrm{T} 1$ e H1 mostraram-se iguais. A interpretação desses índices pode ser feita de forma que, se forem escolhidas duas empresas aleatoriamente, há $50 \%$ de chance de elas adotarem o mesmo método contábil.

A segunda abordagem do índice $\mathrm{T}$, que inclui todas as empresas da amostra independentemente da não divulgação, revela um alto nível de comparabilidade, e a terceira abordagem $(0,29)$ revela um nível baixo de comparabilidade. Já a segunda abordagem do índice $\mathrm{H}$, que também inclui todas as empresas da amostra, revelou uma comparabilidade baixa por meio do valor de 0,35.

\section{CONCLUSÕES}

As normas internacionais (International Financial Reporting Standards - IFRS), emitidas pelo Internacional Accounting Standards Board (IASB), representaram o ponto de partida para o processo de harmonização dos padrões contábeis, visando atender ao crescimento dos mercados de capitais e, consequentemente, à exigência por informações cada vez mais relevantes para a tomada de decisão dos usuários.

Uma das características qualitativas que fornecem maior relevância e utilidade às informações contábeis é a comparabilidade, permitindo a comparação de informações entre entidades diferentes ou entre a mesma entidade em períodos de tempo distintos. Assim, a existência de escolhas contábeis, também conhecidas como accounting choices, pode influenciar negativamente a qualidade da informação.

As propriedades para investimento - regulamentadas pelo Pronunciamento Técnico 28 (CPC, 2009) - são aquelas mantidas para aluguel e/ou valorização de capital e caracterizamse como um dos casos de escolhas contábeis permitidas pelas normas internacionais. Por meio do questionamento da influência que métodos alternativos de contabilização podem ter sobre a característica de comparabilidade, o estudo teve como objetivo verificar o nível de comparabilidade da mensuração após o reconhecimento inicial das PPI das companhias abertas listadas na B3. A amostra foi composta por 91 empresas listadas em dez setores distintos da B3, que representam aquelas com saldos de PPI no exercício social de 2015 dentre uma população de 457 empresas. 
Buscando atingir o objetivo específico (i) para identificar o método utilizado na mensuração das PPI, verificou-se que a maioria das empresas aplica o método de custo (40\%), porém com pouca diferença para o método de valor justo (33\%), e que grande parte não divulga o método contábil utilizado (24\%), desobedecendo a uma das obrigatoriedades de divulgação, conforme o CPC 28 (2009).

Os resultados encontrados em relação à predominância do método de custo na mensuração posterior ao reconhecimento inicial das propriedades vão ao encontro dos estudos de Costa et al. (2013), Andrade et al. (2013) e Botinha e Lemes (2016). Além disso, observouse que $100 \%$ do setor de Telecomunicações - apesar de incluir apenas uma empresa - adotou o método de custo, validando o artigo de Botinha e Lemes (2016), que verificou a redução da probabilidade de uma empresa aplicar o valor justo se pertence ao setor de Telecomunicações.

Por meio da investigação do objetivo específico (ii), constatou-se que, dentre as 36 empresas pertencentes à amostra que aplicaram o método de custo na mensuração das PPI, $58 \%$ divulgaram o valor justo para atender à finalidade de divulgação prevista no CPC 28 (2009). As empresas dos setores de Bens Industriais, Materiais Básicos, Saúde, Tecnologia da Informação e Telecomunicações atenderam $100 \%$ à finalidade de divulgação do valor justo, enquanto as empresas do setor de Consumo Cíclico foram as que apresentaram menor índice de divulgação (20\%). Dessa forma, os dados são próximos aos encontrados por Botinha e Lemes (2016): 55\% das empresas respeitaram a finalidade de divulgação do valor justo. Costa et al. (2013) concluíram que $68 \%$ das empresas optantes pelo método de custo divulgaram o valor justo, um índice maior do que o verificado neste estudo.

Para atingir o objetivo específico (iii), ou seja, analisar o nível de comparabilidade das companhias abertas listadas na B3, foram utilizadas as três abordagens do índice $\mathrm{T}$ de harmonia, proposto por Taplin (2004), e duas abordagens do índice H, introduzido por Van der Tas (1988). A amostra em geral apresentou um nível médio de comparabilidade na primeira abordagem dos dois índices que desconsidera as empresas que não divulgaram o método, porém com valor bem próximo a um nível baixo. A interpretação de T1 e H1 $(0,50)$ pode ser feita de maneira que, se duas empresas forem selecionadas aleatoriamente, há $50 \%$ de chance de elas adotarem o mesmo método contábil. Em relação à segunda abordagem do índice $\mathrm{T}$, que inclui todas as empresas, registrou-se uma comparabilidade alta, e a terceira uma comparabilidade baixa. Quanto à segunda abordagem do índice $H$, foi revelada uma comparabilidade baixa. O estudo corrobora a pesquisa de Souza et al. (2015), que verificou um grau médio de comparabilidade nas empresas brasileiras quanto à mensuração das PPI. Destaca-se que, para a presente pesquisa, como não se busca verificar o nível de comparabilidade entre países, o índice $\mathrm{H}$ fornece os subsídios necessários.

Conclui-se que, apesar da adoção das normas internacionais IFRS no Brasil por meio da Lei no 11.638/2007 e do processo de harmonização dos padrões contábeis, algumas empresas pertencentes à B3 ainda não respeitam o Pronunciamento Técnico 28 (2009) em sua totalidade, não divulgando o método de mensuração das PPI ou até mesmo não atendendo à finalidade de divulgação do valor justo. Além disso, alguns setores apresentaram um nível alto de comparabilidade observado pelo índice $\mathrm{T}$, porém os dois setores com maior número de empresas apresentaram um nível médio muito próximo a um nível baixo.

Nesse aspecto, concordando com o estudo de Costa et al. (2013), identifica-se um problema de comparabilidade das informações contábeis, uma vez que o nível de conformidade de divulgação, conforme o CPC 28 (2009), ainda não atingiu sua totalidade, e empresas de mesmos setores apresentam diferentes escolhas contábeis na mensuração das PPI. Além disso, assim como destacado no estudo de Silva et al. (2014), foram encontradas dificuldades de evidenciação dessas propriedades em demonstrações e notas explicativas, prejudicando a tomada de decisão de usuários da informação contábil.

$\mathrm{O}$ artigo apresentou como limitações $\mathrm{O}$ ano de análise das demonstrações financeiras padronizadas das empresas da B3, a aplicação de dois índices de comparabilidade e a verificação de apenas dois itens obrigatórios de divulgação, conforme o CPC 28 (2009). Recomenda-se, assim, para estudos posteriores, a ampliação do período de estudo, a aplicação de outros índices de comparabilidade ou modelos estatísticos e a verificação de outros itens obrigatórios para a conformidade segundo o CPC 28 (2009). 


\section{REFERÊNCIAS}

Andrade, M. E. M. C., Silva, D. M. da, \& Malaquias, R. F. (2013). Escolhas contábeis em propriedades para investimento. Revista Universo Contábil, 9(3), 22-37.

Araújo, T. S., Souza, F. Ê. A., \& Lemes, S. (2015). O impacto das escolhas contábeis na comparabilidade das demonstrações financeiras de companhias abertas com programa de fidelização de clientes. REUNIR: Revista de Administração, Contabilidade e Sustentabilidade, 5(2), 43-61.

Botinha, R. A., Santos, C. K. S., \& Lemes, S. (2013). O uso das escolhas contábeis na mensuração do ativo biológico: um estudo comparativo entre companhias abertas brasileiras. Anais do Seminários em Administração, São Paulo, Brasil, 16.

Botinha, R. A., \& Lemes, S. (2016). Escolha do uso do valor justo para propriedades para investimentos: uma influência das características de empresas listadas na BM\&FBovespa e na NYSE. Advances in Scientific \& Applied Accounting, 9(1), 22-40.

Cairns, D., Massoudi, D., Taplin, R., \& Tarca, A. (2011). IFRS fair value measurement and accounting policy choice in the United Kingdom and Australia. The British Accounting Review, 43(1), 1-21.

Coelho, L. V., Campagnoni, M., \& Rover, S. (2016). Nível de comparabilidade das práticas contábeis dos estoques de empresas do ramo varejista listadas na BM\&FBovespa. Anais do Congresso de Iniciação Científica em Contabilidade da UFRGS, Porto Alegre, RS, Brasil, 1.

Cole, V., Branson, J., \& Breesch, D. (2008). An analysis of methods to measure the comparability of the consolidated financial statements of the European listed companies from the viewpoint of user. Accountancy \& Bedrijfskunde, 28(3), 1-31.

Cole, V., Branson, J., \& Breesch, D. (2009). How to measure the comparability of financial statements?. International Journal of Managerial and Financial Accounting, 1(4), 379-397.

Comitê de Pronunciamentos Contábeis. (2009). Pronunciamento Técnico CPC 28: Propriedade para Investimento. Recuperado em 15 dezembro, 2016, de http://www.cpc.org.br/CPC/Documentos-Emitidos/Pronunciamentos/Pronunciamento?ld= 59

Comitê de Pronunciamentos Contábeis. (2011). Pronunciamento Técnico CPC 00 (R1) Estrutura Conceitual para Elaboração e Divulgação de Relatório Contábil-Financeiro. Recuperado em 25 novembro, 2016, de http://www.cpc.org.br/CPC/DocumentosEmitidos/Pronunciamentos/Pronunciamento? $\mathrm{ld}=80$

Costa, T. D. A., Silva, A. H. C., \& Laurencel, L. D. C. (2013). Escolha de práticas contábeis: um estudo sobre propriedades para investimento em empresas brasileiras não financeiras de capital aberto. Revista de Contabilidade e Organizações, 7(18), 25-36.

Fearnley, N., \& Gray, S. (2015). National institutional factors and IFRS Implementation in Europe: The case of investment property companies. International Journal of Accounting and Information Management, 23(3), 271-288.

Fields, T. D., Lys, T. Z., \& Vincent, L. (2001). Empirical research on accounting choice. Journal of Accounting and Economics, 31(1), 255-307. 
Gil, A. C. (2008). Métodos e técnicas de pesquisa social (6a ed. p. 28). São Paulo: Atlas.

Kolozsvari, A. C., Marques, J. A. V. D. C., \& Macedo, M. A. D. S. (2014). Escolhas contábeis: análise dos efeitos da mensuração a custo ou a valor justo das propriedades para investimento sobre o desempenho reportado no segmento de exploração imobiliária. Pensar Contábil, 16(61), 18-27.

Kwinto, P. P., \& Voss, G. (2016). Investment Property in the Financial Statements of Capital Groups Listed on the Warsaw Stock Exchange. European Journal of Economics and Business Studies, 4(1), 229-236.

Martins, G. D. A., \& Theóphilo, C. R. (2009). Metodologia da investigação científica para ciências sociais aplicadas (2a ed.). São Paulo: Atlas.

Pereira, A. F. (2013). Determinantes na escolha do valor justo para propriedades para investimento no Brasil. São Paulo. Dissertação de Mestrado, Programa de PósGraduação em Controladoria e Contabilidade, Universidade de São Paulo (USP), São Paulo Brasil. Recuperado em 15 janeiro, 2017, de http://www.teses.usp.br/teses/disponiveis/12/12136/tde-25032013-161045/pt-br.php

Pinto, M. J. T., Martins, V. A., \& da Silva, D. M. (2015). Escolhas contábeis: o caso brasileiro das propriedades para investimento. Revista Contabilidade \& Finanças, 26(69), 274-289.

Silva, J. D., Fonseca, L. D. M., \& Nogueira, D. R. (2014). Nível de conformidade do pronunciamento CPC 28: uma análise nas companhias abertas brasileiras. Revista Catarinense da Ciência Contábil, 13(40), 54-66.

Souza, F. E. A., Silva, M. H., \& Costa, P. S. (2013). A comparabilidade das escolhas contábeis na avaliação de ativos intangíveis de companhias abertas brasileiras. Anais do Seminários em Administração, São Paulo, Brasil, 16.

Souza, F. E. A., Botinha, R. A., Silva, P. R., \& Lemes, S. (2015). A comparabilidade das escolhas contábeis na avaliação posterior de propriedades para investimento: uma análise das companhias abertas brasileiras e portuguesas. Revista Contabilidade \& Finanças, 26(68), 154-166.

Souza, F. E. A., Silva, M. H., \& Rech, I. J. (2015). O impacto das escolhas contábeis na comparabilidade dos ativos imobilizados de companhias abertas no Brasil. Revista Capital Científico - Eletrônica (RCCe), 13(3), 93-110.

Souza, F. E. A., \& Lemes, S. (2016). A comparabilidade das escolhas contábeis na mensuração subsequente de ativos imobilizados, de ativos intangíveis e de propriedades para investimento em empresas da América do Sul. Revista Contabilidade \& Finanças, 27(71), 169-184.

Taplin, R. H. (2004). A unified approach to the measurement of international accounting harmony. Accounting and Business Research, 34(1), 57-73.

Taplin, R. H, Yuan, W., \& Brown, A. (2014). The use of fair value and historical cost accounting for investment properties in China. Australasian Accounting Business \& Finance Journal, $8(1), 101-113$.

Thomaz, J. L. P., Kronbauer, C. A., \& Schneider, L. C. (2015). Estudo das normas e práticas contábeis adotados pelas empresas industriais do Mercosul e Comunidade Andina: convergência referente a mensuração e evidenciação das propriedades para 
investimento. Revista de Contabilidade do Mestrado em Ciências Contábeis da UERJ, 19(3), 2-18.

Van der Tas, L. G. (1988). Measuring harmonisation of financial reporting practice. Accounting and business research, 18(70), 157-169.

Vaz, A. C., Gonçalves, R. S., Niyama, J. K., \& Gonçalves, A. O. (2010). Análise comparativa sobre informações voluntárias divulgadas: o social disclosure das empresas latinoamericanas listadas na Nyse. Revista de Educação e Pesquisa em Contabilidade (REPeC), 4(1), 38-59.

Watts, R., \& Zimmerman, J. (1986). Teoria contábil positiva. Recuperado em 15 janeiro, 2017, de https://papers.ssrn.com/sol3/papers.cfm?abstract_id=928677 